\title{
Characterization of glacial rock \\ flour and assessment of its enhanced weathering potential
}

\author{
SNEHA RAY SARKAR ${ }^{1 *}$, SØREN JESSEN ${ }^{2}$, ASTRID \\ VESTER-EBBESEN ${ }^{2}$, NYNKE KEULEN ${ }^{3}$, KNUD \\ DIDERIKSEN $^{3}$, MINIK T. ROSING ${ }^{1}$
}

${ }^{1}$ GLOBE Institute, University of Copenhagen, Øster

Voldgade 5-7, 1350 Copenhagen, Denmark

(*correspondence: sneha.sarkar@sund.ku.dk)

${ }^{2}$ Department of Geosciences and Natural Resource

Management (IGN), University of Copenhagen, Øster

Voldgade 10, 1350 Copenhagen, Denmark

${ }^{3}$ Geological Survey of Denmark and Greenland (GEUS),

Øster Voldgade 10, 1350 Copenhagen, Denmark

Glacial meltwater annually transports several megatons of sediments carrying clay-sized mineral particles, referred to as glacial rock flour (GRF), to proglacial environments or the ocean. We characterized GRF of marine deposits from the Greenlandic Ice Sheet meltwater exports in Western Greenland. The GRF showed a median size range of $2-11 \mu \mathrm{m}$ and a BET surface area range of $10-20 \mathrm{~m}^{2} \mathrm{~g}^{-1}$. Based on scanning electron microscopy, GRF was found to be composed mainly of the primary bedrock minerals oligoclase (13.2-31\%), quartz $(6.5-25 \%)$, biotite $(7.2-28 \%)$, anorthite (6.0-13\%), K-feldspar (2.2-7.4\%), amphiboles (5.7-11\%) and muscovite $(1.2-1.9 \%)$. This mineralogy and grain size characteristics suggested GRF to be an excellent candidate for enhanced weathering. Therefore, the carbon capturing efficacy of GRF from an uplifted Holocene marine deposit (BET surface area $15 \mathrm{~m}^{2} \mathrm{~g}^{-1}$ ) near Nuuk, Greenland was investigated. We compared its dissolution kinetics in deionized water in equilibrium with the ambient $\mathrm{pCO}_{2}$ of $0.00040 \mathrm{~atm}$ and with an increased $\mathrm{pCO}_{2}$ of $0.05 \mathrm{~atm}$. The electrical conductivity and $\mathrm{pH}$ of the continuously-stirred suspension were measured at regular intervals, and aliquots from it were filtered and analysed for $\mathrm{Si}, \mathrm{Na}, \mathrm{Ca}, \mathrm{Mg}, \mathrm{K}, \mathrm{Al}$, $\mathrm{P}, \mathrm{S}$ and $\mathrm{Fe}$. A higher $\mathrm{pCO}_{2}$ facilitated a higher cation-release rate and after $1000 \mathrm{hrs}$, resulted in alkalinities $\sim 0.6 \mathrm{mEqv} \mathrm{L}^{-1}$. Less than $1 \%$ of the total solid pool of major cations and $\mathrm{Si}$ was released during the experiment, and all cation-release curves reached a plateau except $\mathrm{Si}$, which showed a continuous increase. $\mathrm{Al}$ and $\mathrm{Fe}$ in the solution maintained low values indicating immediate scavenging by secondary minerals. 